\title{
Article
}

\section{In-Season Body Composition Effects in Professional Women Soccer Players}

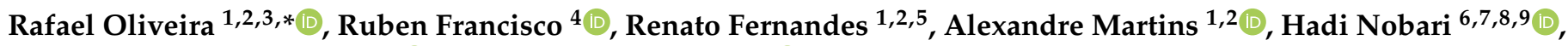 \\ Filipe Manuel Clemente ${ }^{10,11([)}$ and João Paulo Brito ${ }^{1,2,3}$ (B)
}

1 Sports Science School of Rio Maior-Polytechnic Institute of Santarém, 2040-413 Rio Maior, Portugal; rfernandes@esdrm.ipsantarem.pt (R.F.); alexandremartins@esdrm.ipsantarem.pt (A.M.); jbrito@esdrm.ipsantarem.pt (J.P.B.)

2 Life Quality Research Centre, 2040-413 Rio Maior, Portugal

3 Research Center in Sport Sciences, Health Sciences and Human Development, 5001-801 Vila Real, Portugal

4 Exercise and Health Laboratory, CIPER, Faculdade Motricidade Humana, Universidade de Lisboa, 1499-002 Lisbon, Portugal; ruben92francisco@gmail.com

5 University of Trás-os-Montes e Alto Douro, 5001-801 Vila Real, Portugal

6 Department of Exercise Physiology, Faculty of Educational Sciences and Psychology, University of Mohaghegh Ardabili, Ardabil 56199-11367, Iran; hadi.nobari1@gmail.com

7 HEME Research Group, Faculty of Sport Sciences, University of Extremadura, 10003 Cáceres, Spain

8 Sports Scientist, Sepahan Football Club, Isfahan 81887-78473, Iran

9 Department of Physical Education and Sports, University of Granada, 18010 Granada, Spain

10 Escola Superior Desporto e Lazer, Instituto Politécnico de Viana do Castelo, Rua Escola Industrial e Comercial de Nun'Álvares, 4900-347 Viana do Castelo, Portugal; filipe.clemente5@gmail.com

11 Instituto de Telecomunicações, Delegação da Covilhã, 1049-001 Lisboa, Portugal

* Correspondence: rafaeloliveira@esdrm.ipsantarem.pt

Citation: Oliveira, R.; Francisco, R.; Fernandes, R.; Martins, A.; Nobari,

H.; Clemente, F.M.; Brito, J.P.

In-Season Body Composition Effects in Professional Women Soccer Players. Int. J. Environ. Res. Public Health 2021, 18, 12023. https://doi.org/10.3390/ ijerph182212023

Academic Editor: Paul B. Tchounwou

Received: 25 October 2021

Accepted: 15 November 2021

Published: 16 November 2021

Publisher's Note: MDPI stays neutral with regard to jurisdictional claims in published maps and institutional affiliations.

Copyright: (c) 2021 by the authors Licensee MDPI, Basel, Switzerland. This article is an open access article distributed under the terms and conditions of the Creative Commons Attribution (CC BY) license (https:/ / creativecommons.org/licenses/by/ $4.0 /)$.
Abstract: This study aimed to analyze anthropometric and body composition effects in professional soccer women players across the early and mid-competitive 2019/20 season. Seventeen players (age, height, body mass, and body mass index of $22.7 \pm 6.3$ years, $167.5 \pm 5.6 \mathrm{~cm}, 60.7 \pm 6.6 \mathrm{~kg}$ and $21.6 \pm 0.2 \mathrm{~kg} / \mathrm{m}^{2}$ ) from a Portuguese BPI League team participated in this study. The participants completed $\geq 80 \%$ of 57 training sessions and 13 matches. They were assessed at three points (before the start of the season (A1), after two months (A2), and after four months (A3)) using the following variables: body fat mass (BFM), soft lean mass (SLM), fat-free mass (FFM), intracellular water (ICW), extracellular water (ECW), total body water (TBW), and phase angle (PhA, $50 \mathrm{Khz}$ ), through InBody S10. Nutritional intake was determined through a questionnaire. Repeated measures ANCOVA and effect sizes (ES) were used with $p<0.05$. The main results occurred between A1 and A2 for $\operatorname{BFM}(-21.7 \%, \mathrm{ES}=1.58), \mathrm{SLM}(3.7 \%, \mathrm{ES}=1.24), \mathrm{FFM}(4 \%, \mathrm{ES}=1.34), \mathrm{ICW}(4.2 \%, \mathrm{ES}=1.41), \mathrm{TBW}$ $(3.7 \%$, ES $=1.04)$. Furthermore, there were significant results between A1 and A3 for FFM $(4.8 \%$, $\mathrm{ES}=1.51)$ ICW $(5 \%, \mathrm{ES}=1.68)$, and $\mathrm{PhA}(10.4 \%, \mathrm{ES}=6.64)$. The results showed that the water parameters improved over time, which led to healthy hydration statuses. The training load structure provided sufficient stimulus for appropriate physical fitness development, without causing negative disturbances in the water compartments.

Keywords: phase angle; female; body fat mass; fat-free mass; intracellular water; rated perceived exertion

\section{Introduction}

Soccer is considered one of the most popular sports worldwide [1]. To improve soccer athletes' performance and health, the assessment of anthropometric and body composition variables have been considered crucial [2]. Especially at a competitive level, body composition is an important component in an athlete's fitness and health profile and in each sport, performance is improved in specific ways in order to prevent injury risk [3].

Special attention has been paid to body fat mass (BFM) and fat-free mass (FFM). It is well known that an increased fat mass compromises performance, while increased muscle 
mass can promote the development of strength and power, which are important for players' performance [4-6]. According to a recent consensus statement, there are no values for BFM or FFM that should be followed, even more if we consider female soccer players [6]. For instance, in female player from US collegiate division 1, BFM of $16 \%$ was observed. In fact, the consensus statement added that it is not known what kind of body composition changes during the season may impact positively or negatively on the performance of the players [6].

Moreover, the interest in assessing other body composition variables, such as total body water (TBW), intracellular water (ICW), and extracellular water (ECW), to monitor hydration status in athletes has grown. For example, some studies have shown that ICW is a good predictor of strength and power in athletes [7-9].

Thus, considering the importance of body composition for athletes, frequent assessments should take place. This will allow coaches and athletes to know the development of body composition throughout the sports season and adjust training programs to prevent injuries and enhance sports performance.

Over the last decades, women's participation in sports has greatly increased. Although scientific research on women soccer athletes is growing, it is still limited [5,10-13]. Coaches and sports-related professionals should be aware of gender-specific questions and needs for optimizing performance. Especially at an elite level, few data have been used to show changes in anthropometric and body composition in women soccer players during the in-season [14]. To the knowledge of the authors, if the variables mentioned above and the training load variables, such as rated perceived exertion (RPE), were considered simultaneously, no studies were found. According to a recent report, performance measured by training and/or match data and body composition assessment could help soccer coaches and their staff to provide proper information for each player [6].

Specifically, internal load, which is one of the two dimensions of load monitoring (the other is external load), is a crucial psychophysiological part of the training load monitoring processes. One of the most frequently used variables to access internal load is RPE or the session-RPE (s-RPE, multiplication of RPE by session duration). This measure is a valid, reliable, and sensitive approach to quantify and qualify the internal load while using a simple questionnaire [15].

Knowledge of the essential characteristics for successful women's team soccer performance is useful to coaches, physicians, nutritionists, and exercise physiologists to improve their knowledge about women soccer athletes.

Therefore, this study aims to analyze the variations on anthropometric and body composition variables and their relationship with internal load in elite women soccer players across early and mid-competitive in-season using bioelectrical impedance analysis (BIA).

\section{Materials and Methods}

\subsection{Experimental Approach to the Problem}

This was an analytical and observational cohort study. The training sessions were performed during a five-month period, from September to January (early-to-mid-season) due to the COVID-19 pandemic, which provoked the disruption of training sessions and matches and the suspension of the season in March. The anthropometric and body composition assessments were conducted on three different occasions: the first week of September (before the start of the season, A1), after two months (the second week of November, A2), and two months after A2 (the third week of January, A3). All the assessments were performed under the same room and environmental conditions (place, time of day, order of tests application, temperature, and relative humidity, respectively, $22-24{ }^{\circ} \mathrm{C}$ and $55-65 \%$ ) and by the same examiner. The players did not perform any other complementary training sessions during the period analyzed. 


\subsection{Participants}

Seventeen elite women soccer players with a mean \pm standard deviation age, height, body mass, and body mass index of $22.7 \pm 6.3$ years, $167.5 \pm 5.6 \mathrm{~cm}, 60.7 \pm 6.6 \mathrm{~kg}$, and $21.6 \pm 0.2 \mathrm{~kg} / \mathrm{m}^{2}$, respectively, participated in this study. Their experience as professional soccer players was $4.7 \pm 2.2$ years.

We estimated the power of the sample size using a post hoc F-test: the within-group factor in a repeated-measures MANOVA, according to statistical method analyzed. The analysis featured $94.2 \%$ of actual power, with a total of 17 women soccer players with a $p<0.05$ and effect-size for 0.6, using G-Power [16].

The players belonged to a team that participated in the Portuguese BPI League during the 2019/20 in-season. The inclusion criteria were regular participation in most of the training sessions ( $80 \%$ of the weekly training sessions) and the completion of at least half the matches in the first half of the season [17], while the exclusion criteria were injury, illness, sickness, and/or non-performance of all the assessments. Due to the exclusion criteria, only sixteen women soccer players participated in the present study. The field positions of the players in the study consisted of one goalkeeper, three central defenders (CD), three wide defenders (WD), three central midfielders (CM), four wide midfielders (WM) and three strikers (ST).

Despite the different characteristics of the soccer field players, the goalkeeper was included in the analysis, since all the data collected for this player were similar to the squad average and the players' position values, and it was not detected as an outlier. All the participants were familiarized with the training protocols and the study design was carefully explained to the athletes. Written informed consent was obtained prior to the investigation.

A food frequency questionnaire to assess nutritional intake was applied over a 7 day period using a $24 \mathrm{~h}$ diet record, during the first week of the assessment 1 and during the last week of the assessment 3 , in order for the players to verify their habits and food regimen routines.

The participants were instructed regarding portion sizes, supplements, food preparation aspects, and other aspects pertaining to an accurate recording of their energy intake. The records were reviewed for macronutrient composition and total energy intake [7]. All the participants were asked to maintain their normal diet throughout the study period.

The study was conducted according to the requirements of the Declaration of Helsinki and all the procedures were approved by the research Ethics Committee of the Polytechnic Institute of Santarém, Santarém, Portugal. All the subjects received their club's medical approval to participate in the study and were instructed not to take any medication during the study.

\subsection{Procedures}

The data were collected in weeks with only one match, which means that the team typically trained three days a week (match day minus (-); MD-5; MD-4; MD-2). This approach was used in a previous study [17]. During the period analyzed, a total of 57 training sessions and 13 matches occurred. The 57 training sessions were divided into 19 speed endurance sessions (e.g., long sprints, repeated sprints), 19 aerobic high-intensity sessions (e.g., interval training, medium-to-large sized games), and 19 ball-possession games and team/opponent tactics sessions. Figure 1 presents the timeline of the study.

In order to produce more specific information regarding training and match load, rated perceived exertion (RPE) and the duration of training sessions and matches were collected and presented in Table 1 to quantify training load. The data are presented by squad average between the different assessments. On match days (MD) only the average data for starters were included. 
ASSESSMENTS

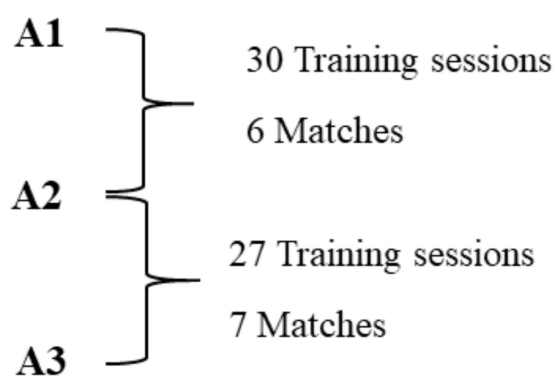

Figure 1. Timeline of the study. Legend: A1. Assessment 1; A2. Assessment 2; A3. Assessment 3.

Table 1. Training and match RPE and duration between the three assessments.

\begin{tabular}{cccccccc}
\hline Periods & Variables & MD-5 & MD-4 & MD-3 & MD-2 & MD-1 & MD \\
\hline \multirow{3}{*}{ Between A1 and A2 } & RPE (au) & 5.5 & 5.4 & $X$ & 4.8 & $X$ & 6.2 \\
& Duration (min) & 87 & 85 & $X$ & 77 & $X$ & 72 \\
& s-RPE (au) & 478.5 & 459 & $X$ & 396.6 & $X$ & 446.4 \\
\hline \multirow{3}{*}{ Between A2 and A3 } & RPE (au) & 6.1 & 5.5 & $X$ & 4.1 & $X$ & 6.5 \\
& Duration (min) & 85 & 85 & $X$ & 90 & $X$ & 90 \\
& s-RPE (au) & 518.5 & 467.5 & $X$ & 369 & $X$ & 585 \\
\hline
\end{tabular}

A1. Assessment 1; A2. Assessment 2; A3. Assessment 3; MD. Match-day; MD-5. Match minus five days to the match. respectively for $-4,-3,-2$, and -1 . RPE. Rated perceived exertion; s-RPE. Session rated perceived exertion; au. Arbitrary units; min. Minutes. X indicates day off.

\subsection{Anthropometric and Body Composition Assessment}

Based on previous recommendations, the anthropometric and body composition measures were obtained with the subjects dressed in light clothing without shoes [18,19]. The participants were further asked to remove all objects that could interfere with the bioelectrical impedance assessment. The participants' weight and height were measured using a stadiometer with an incorporated scale (Seca 220, Hamburg, Germany) according to standardized procedures [20]. The body composition data were obtained with bioelectrical impedance analysis through Inbody S10 (model JMW140, Biospace Co, Ltd., Seoul, Korea), according to manufacturer's guidelines [21,22] and the recommendations of a previous study [23]. Eight electrodes were placed on eight tactile points (thumbs, middle fingers and ankles of both hands and feet, respectively) to perform the multi-segmental frequency analysis. Next, a total of 30 impedance measurements were obtained at frequencies 1 , $5,50,250,500$, and $1000 \mathrm{kHz}$, respectively, from different segments of the body, such as the right and left arms, trunk, and right and left legs, respectively. Moreover, three different frequencies $(5,50$, and $250 \mathrm{kHz})$ were used to collect the 15 reactance, $\mathrm{PhA}$ measurements from the right and left arms, trunk, and right and left legs, respectively. The variables collected were: body fat mass (BFM), soft lean mass (SLM), fat-free mass (FFM), intracellular water (ICW), extracellular water (ECW), total body water (TBW), phase angle (PhA, $50 \mathrm{Khz}), \mathrm{ECW} / \mathrm{TBW}$ ratio, and ECW/ICW.

The measurements were carried out in the morning [18,24], in a room with an ambient temperature and relative humidity of $22-23^{\circ} \mathrm{C}$ and $50-60 \%$, respectively, after a minimum of $8 \mathrm{~h}$ of fasting and after the bladder was emptied. The participants adopted a supine position with their arms and legs abducted at a $45^{\circ}$ angle, and the right hand and foot dorsal surfaces were cleaned with alcohol. After a $10 \mathrm{~min}$ rest in a room without noise, eight electrodes were placed on the cleaned surfaces and the measurements were performed. The subjects did not exercise or ingest caffeine or alcohol during the $12 \mathrm{~h}$ prior to the assessment and they were only assessed if they were in the luteal phase of ovulatory menstrual cycles. Otherwise, they waited for more days, until they were in the luteal phase. 
All the assessments were performed by the same evaluator in order to minimize possible measurement errors [25].

\subsection{Training and Match Load Quantification}

Thirty minutes after the end of each training session and match, the players were asked to provide an RPE (0-10 scale) [26]. The players were prompted for their RPE individually using a custom-designed application on a portable computer tablet. They selected their RPE rating by touching the respective score on the tablet, which was then automatically saved under the player's profile. This method helped to minimize factors that may have influenced the player's RPE rating, such as peer pressure and replicating other players' ratings [27]. Next, the s-RPE was calculated, as in our previous studies, through the multiplication of the session duration by the RPE [28,29].

\subsection{Statistical Procedures}

Descriptive statistics (mean \pm standard deviation) were performed for all the measurements. All the variables were checked for normality and homoscedasticity, respectively, using the Shapiro-Wilk and Levene tests. The MANOVA with repeated measures was performed for the variables that obtained normal distribution to compare the three assessments, with s-RPE being used as covariate. The value of $p \leq 0.05$ was established as significant and all the data were analyzed using SPSS version 22.0 (SPSS Inc., Chicago, IL, USA) for the Windows statistical software package. Furthermore, the change (\%) was calculated between each comparison. The Cohen's d effect-size (ES) was performed to determine the effect magnitude through the difference of two means divided by the standard deviation from the data, and the following criteria were used: $<0.2=$ trivial, 0.2 to $0.6=$ small effect, 0.6 to $1.2=$ moderate effect, 1.2 to $2.0=$ large effect, and $>2.0=$ very large [30].

\section{Results}

Table 2 summarizes the participants' characteristics by player position, while Table 3 showed comparisons between the three assessments for the squad average.

Table 2. Participant characteristics by player position in the three assessments.

\begin{tabular}{|c|c|c|c|c|c|c|}
\hline Variables & $\begin{array}{c}\text { Goalkeeper } \\
\qquad \begin{array}{c}n=1 \\
\text { n }\end{array}\end{array}$ & $\begin{array}{c}\text { Central } \\
\text { Defender } \\
n=3\end{array}$ & $\begin{array}{c}\text { Wide } \\
\text { Defender } \\
n=3\end{array}$ & $\begin{array}{c}\text { Central } \\
\text { Midfielder } \\
n=3\end{array}$ & $\begin{array}{c}\text { Wide } \\
\text { Midfielder } \\
n=4\end{array}$ & $\begin{array}{c}\text { Striker } \\
n=3\end{array}$ \\
\hline \multicolumn{7}{|c|}{ Assessment 1} \\
\hline Body weight (kg) & 64.0 & $71.0 \pm 2.0$ & $54.3 \pm 3.8$ & $59.3 \pm 9.2$ & $53.5 \pm 8.7$ & $57 \pm 1.0$ \\
\hline Body fat mass (kg) & 15.3 & $18.7 \pm 2.3$ & $12.4 \pm 1.4$ & $14.1 \pm 5.4$ & $11.1 \pm 4.5$ & $8.1 \pm 2.0$ \\
\hline Soft lean mass (kg) & 45.9 & $49.1 \pm 2.1$ & $39.3 \pm 2.3$ & $42.5 \pm 3.6$ & $39.9 \pm 5.1$ & $46.0 \pm 2.9$ \\
\hline Fat free mass (kg) & 48.7 & $52.3 \pm 2.2$ & $41.9 \pm 2.4$ & $45.2 \pm 3.9$ & $42.5 \pm 5.4$ & $48.9 \pm 3.0$ \\
\hline Intracellular Water (L) & 22.4 & $23.8 \pm 0.9$ & $19.1 \pm 1.3$ & $20.6 \pm 1.9$ & $19.3 \pm 2.4$ & $22.4 \pm 1.3$ \\
\hline Extracellular Water (L) & 13.2 & $14.4 \pm 0.8$ & $11.4 \pm 0.6$ & $12.5 \pm 1.0$ & $11.7 \pm 1.5$ & $13.3 \pm 1.0$ \\
\hline Total Body Water (L) & 35.6 & $38.2 \pm 1.7$ & $35.5 \pm 1.8$ & $33.1 \pm 2.8$ & $31.0 \pm 4.0$ & $35.7 \pm 2.3$ \\
\hline Phase Angle ( $\theta .50 \mathrm{Khz})$ & 6.8 & $6.0 \pm 0.3$ & $6.3 \pm 0.6$ & $6.3 \pm 0.5$ & $6.0 \pm 0.3$ & $6.4 \pm 0.3$ \\
\hline \multicolumn{7}{|c|}{ Assessment 2} \\
\hline Body weight (kg) & 67.0 & $69.3 \pm 1.2$ & $53.7 \pm 3.2$ & $58.0 \pm 6.9$ & $53.5 \pm 7.9$ & $57.0 \pm 2.0$ \\
\hline Body fat mass (kg) & 15.8 & $14.1 \pm 2.6$ & $8.8 \pm 4.2$ & $10.2 \pm 1.9$ & $10.9 \pm 3.7$ & $6.7 \pm 1.8$ \\
\hline Soft lean mass (kg) & 48.1 & $51.7 \pm 2.1$ & $42.0 \pm 6.0$ & $44.8 \pm 4.9$ & $39.9 \pm 5.3$ & $47.2 \pm 3.5$ \\
\hline Fat free mass (kg) & 51.2 & $55.3 \pm 2.3$ & $44.9 \pm 6.2$ & $47.8 \pm 5.1$ & $42.6 \pm 5.6$ & $50.3 \pm 3.7$ \\
\hline Intracellular Water (L) & 23.5 & $25.2 \pm 1.1$ & $20.5 \pm 3.0$ & $21.8 \pm 2.4$ & $19.4 \pm 2.7$ & $23.1 \pm 1.7$ \\
\hline Extracellular Water (L) & 13.9 & $15.0 \pm 0.6$ & $12.1 \pm 1.6$ & $13.1 \pm 1.3$ & $11.6 \pm 1.4$ & $13.6 \pm 1.1$ \\
\hline Total Body Water (L) & 37.4 & $40.1 \pm 1.7$ & $32.6 \pm 4.6$ & $34.8 \pm 3.7$ & $31.0 \pm 4.1$ & $36.7 \pm 2.8$ \\
\hline Phase Angle ( $\theta .50 \mathrm{Khz})$ & 6.8 & $6.5 \pm 0.6$ & $7.8 \pm 2.6$ & $6.6 \pm 0.7$ & $6.2 \pm 0.4$ & $6.7 \pm 0.2$ \\
\hline
\end{tabular}


Table 2. Cont.

\begin{tabular}{|c|c|c|c|c|c|c|}
\hline Variables & $\begin{array}{c}\text { Goalkeeper } \\
\qquad \begin{array}{c}n=1 \\
\text { n }\end{array}\end{array}$ & $\begin{array}{c}\text { Central } \\
\text { Defender } \\
n=3\end{array}$ & $\begin{array}{c}\text { Wide } \\
\text { Defender } \\
n=3\end{array}$ & $\begin{array}{c}\text { Central } \\
\text { Midfielder } \\
n=3\end{array}$ & $\begin{array}{c}\text { Wide } \\
\text { Midfielder } \\
n=4\end{array}$ & $\begin{array}{c}\text { Striker } \\
n=3\end{array}$ \\
\hline \multicolumn{7}{|c|}{ Assessment 3} \\
\hline Body weight (kg) & 67 & $69.0 \pm 2.6$ & $53 \pm 4.4$ & $57.0 \pm 6.2$ & $53.8 \pm 7.4$ & $59.0 \pm 1.7$ \\
\hline Body fat mass (kg) & 15.4 & $12.1 \pm 3.6$ & $8.0 \pm 2.8$ & $12.2 \pm 3.6$ & $9.4 \pm 3.1$ & $8.7 \pm 1.7$ \\
\hline Soft lean mass (kg) & 48.4 & $53.3 \pm 5.4$ & $42.2 \pm 2.6$ & $42.0 \pm 2.6$ & $41.5 \pm 4.1$ & $47.2 \pm 2.9$ \\
\hline Fat free mass $(\mathrm{kg})$ & 51.6 & $56.9 \pm 5.6$ & $45.0 \pm 2.7$ & $44.8 \pm 2.9$ & $44.4 \pm 4.5$ & $50.3 \pm 2.9$ \\
\hline Intracellular Water (L) & 23.7 & $26.1 \pm 2.7$ & $20.6 \pm 1.4$ & $20.4 \pm 1.3$ & $20.1 \pm 2.0$ & $23.1 \pm 1.4$ \\
\hline Extracellular Water (L) & 13.9 & $15.4 \pm 1.4$ & $12.1 \pm 0.6$ & $12.2 \pm 0.7$ & $2.3 \pm 1.3$ & $13.5 \pm 0.8$ \\
\hline Total Body Water (L) & 37.6 & $41.4 \pm 4.1$ & $32.7 \pm 1.9$ & $32.6 \pm 2.0$ & $32.3 \pm 3.3$ & $33.6 \pm 2.2$ \\
\hline Phase Angle ( $\theta .50 \mathrm{Khz})$ & 7.4 & $7.1 \pm 0.6$ & $7.4 \pm 0.5$ & $6.9 \pm 0.3$ & $6.6 \pm 0.2$ & $6.9 \pm 0.3$ \\
\hline
\end{tabular}

Table 3. Comparisons between assessments by squad average $(n=17)$.

\begin{tabular}{|c|c|c|c|c|c|c|}
\hline Variables & A1 & A2 & A3 & $\begin{array}{l}\text { Change \% } \\
\text { (A1-A2) }\end{array}$ & $\begin{array}{l}\text { Change \% } \\
\text { (A2-A3) }\end{array}$ & $\begin{array}{l}\text { Change \% } \\
\text { (A1-A3) }\end{array}$ \\
\hline Body weight (kg) & $58.74 \pm 2.15$ & $58.30 \pm 1.97$ & $58.30 \pm 1.94$ & -0.8 & 0.0 & -0.8 \\
\hline Body fat mass (kg) & $13.11 \pm 1.87 \mathrm{a}$ & $10.77 \pm 0.94$ & $10.38 \pm 0.87$ & -21.7 & -3.8 & -26.3 \\
\hline Soft lean mass $(\mathrm{kg})$ & $42.87 \pm 1.20 \mathrm{a}$ & $44.52 \pm 1.44$ & $44.91 \pm 1.42$ & 3.7 & 0.9 & 4.5 \\
\hline Fat free mass (kg) & $45.63 \pm 1.27$ a.c & $47.52 \pm 1.53$ & $47.92 \pm 1.51$ & 4.0 & 0.8 & 4.8 \\
\hline Intracellular Water (L) & $20.79 \pm 0.58$ a.c & $21.71 \pm 0.72$ & $21.88 \pm 0.71$ & 4.2 & 0.8 & 5.0 \\
\hline Extracellular Water (L) & $12.53 \pm 0.35$ & $12.88 \pm 0.41$ & $13.00 \pm 0.39$ & 2.7 & 0.9 & 3.6 \\
\hline Total Body Water (L) & $33.32 \pm 0.93 a$ & $34.59 \pm 1.12$ & $34.88 \pm 1.09$ & 3.7 & 0.8 & 4.5 \\
\hline ECW/TBW & $0.38 \pm 0.001$ a.c & $0.37 \pm 0.001 \mathrm{~b}$ & $0.37 \pm 0.001$ & -2.7 & 0.0 & -2.7 \\
\hline $\mathrm{ECW} / \mathrm{ICW}$ & $0.60 \pm 0.003 \mathrm{a}$ & $0.59 \pm 0.003$ & $0.59 \pm 0.004$ & -1.7 & 0.0 & -1.7 \\
\hline Phase Angle $(\theta .50 \mathrm{Khz})$ & $6.26 \pm 0.11 c$ & $6.67 \pm 0.31$ & $6.99 \pm 0.10$ & 6.1 & 4.6 & 10.4 \\
\hline
\end{tabular}

A1. Assessment 1; A2. Assessment 2; A3. Assessment 3; ECW. Extracellular water; ICW. Intracellular water; TBW. Total body water. The symbol a denotes significant difference between A1 and A2 $(p<0.05)$. The symbol b denotes significant difference between A2 and A3 $(p<0.05)$. The symbol $\mathrm{c}$ denotes significant difference between A1 and A3 $(p<0.05)$.

After performing ANCOVA with the session's rated perceived exertion (s-RPE) as the covariate, no linear interaction was demonstrated between this variable and any of the other body composition variables $(p>0.05)$. Table 2 shows significant differences between $\mathrm{A} 1$ and A2 with moderate to very large effect, namely, BFM $(p=0.029 ; \mathrm{ES}=1.58)$, SLM $(p=0.018 ; \mathrm{ES}=1.24), \mathrm{FFM}(p=0.010 ; \mathrm{ES}=1.34), \mathrm{ICW}(p=0.007 ; \mathrm{ES}=1.41), \mathrm{TBW}(p=0.018 ;$ $\mathrm{ES}=1.04), \mathrm{ECW} / \mathrm{TBW}(p=0.002 ; \mathrm{ES}=10.00)$, and ECW $/ \mathrm{ICW}(p=0.022 ; \mathrm{ES}=3.33)$.

In addition, there was only a significant difference with very large effect between $\mathrm{A} 2$ and $\mathrm{A} 3$, for ECW $/ \mathrm{TBW}(p=0.001$; ES = 3.33).

Finally, there were significant differences with large to very large effect between A1 and $\mathrm{A} 3$ for $\operatorname{BFM}(p=0.029 ; \mathrm{ES}=1.87), \operatorname{FFM}(p=0.045 ; \mathrm{ES}=1.51), \mathrm{ICW}(p=0.049 ; \mathrm{ES}=1.68)$, $\mathrm{ECW} / \mathrm{TBW}(p=0.013 ; \mathrm{ES}=10.00)$, and $\mathrm{PhA}(p=0.001 ; \mathrm{ES}=6.64)$.

\section{Discussion}

In this study, we aimed to identify changes in the body composition of elite women soccer players during in-season through BIA. Our main findings showed improvements in body composition, namely decreased BFM, increased FFM, and increased PhA; and a better fluid distribution was observed, especially from the first to the last assessment. However, no significant differences were noted between A2 and A3, except for ECW/TBW.

On one hand, BFM has been shown to exert a negative influence in athletes' performance [5]. On the other hand, FFM has been associated with performance improvements [5]. In our study, the athletes showed a significant decrease in BFM and an increase in FFM. These results are similar to those reported in another study [31], which assessed athletes' body composition in 5 time-points during the in-season. Regarding BFM, athletes presented mean values similar to those found by other authors [32] that assessed body composition 
changes pre-to-post-season in women soccer players. However, the authors found that the soccer players lost lean mass tissue over the competitive season that was not recovered during the off-season [32]. These results may be attributed to overtraining or negative energy balance.

Concerning PhA, the present female soccer players showed a mean value of $6.26 \pm 0.11^{\circ}$ in $\mathrm{A} 1,6.67 \pm 0.31^{\circ}$ in $\mathrm{A} 2$, and $6.99 \pm 0.10^{\circ}$ in $\mathrm{A} 3$. All these values are similar to those found in other studies conducted on women athletes or active young populations [33-35]. Furthermore, the values obtained in this study were slightly lower in A1 and A2 compared to those obtained in a study of healthy adult non-athletes [36]. Moreover, PhA has been related to cellular health and integrity [37]. For example, muscle injuries can cause a reduction in PhA which can provoke cell membrane disruption [38,39], which has also been related to body composition $[33,40,41]$. For instance, FFM is directly related with PhA [41]. Indeed, as FFM increased in these athletes, it seems plausible that PhA also increased. An improvement in PhA can be an indicator of good health and cellular integrity and functionality regarding the level of hydration [34]. Another application of PhA is related to cellular energy levels, so the low phase angle is consistent with an inability of cells to store energy, as well as being an indication of breakdown in the selective permeability of cellular membranes. A high PhA is consistent with large quantities of intact cell membranes and body cell mass [42].

Regarding TBW and its compartments, the importance of TBW and ICW in increasing performance in athletes is clear [7-9]. The increment in ICW and TBW in the present study is in line with a previous study that used resistance training in healthy and young adults [35]. In this regard, soccer is characterized by high intensity bouts of activities and movements. Glycogen is an essential substrate during high intensity sports [43]. Therefore, some explanations could be related to cellular hydration by increasing the glycogen storage, since glycogen features great osmotic power (each gram of glycogen is stored in human muscle with at least $3 \mathrm{~g}$ of water) [43]. These results are very important for athletes, since ICW content may stimulate pathways that increase protein synthesis $[44,45]$. ECW did not show any change during the in-season. Furthermore, the ECW/ICW ratio has been used as an indicator of fluid distribution in athletes [7-9,33]. Two recent studies [33,34] found values of $0.7 \pm 0.1$ in women athletes. In our study, the soccer athletes demonstrated mean values of 0.60 in A1, 0.59 in A2, and 0.59 in A3. Lower values of ECW/ICW have been found in athletes has and they have been associated with improved performance [7].

As mentioned earlier, when A2 andA3 were compared, no significant differences were found. These findings could be attributed to the increased training load in the beginning of the in-season that is generally found in soccer teams [46]. The higher training load resulted in body composition improvements in this early phase (between A1 and A2) that were followed by an adaptation in the second phase of the study (between A2 and A3), causing a maintenance of the body composition variables (considering that nutritional intake was controlled). This is important to highlight because in fact training load was higher between $\mathrm{A} 2$ and $\mathrm{A} 3$ without, however, changing any body composition variable.

A relevant finding that should be highlighted regards s-RPE. Through the analysis conducted in the present study, no interaction was observed between s-RPE and any body composition variables, which means that RPE can be dissociated from the physiological process through different psychological mechanisms [47]. As mentioned in previous studies, it seems that RPE was a simplification of the perceived psychophysiological exertion. Consequently, the use of this measure alone did not conclusively capture different sensations and experience of training sessions [47,48]. Furthermore, RPE was collected 30 min after the training sessions and that value included the entire session. This means that there could be some possible variation during training sessions in different exercises, as suggested by Ferraz et al. [48], that were not controlled in this study. This explanation may help to explain the non-interaction found regarding this variable in this study. It also reinforces the use of additional variables in training load monitoring, such as distances covered at different intensities, accelerations, decelerations, player load and metabolic power. 
Scientific research on women soccer athletes is scarce [10,11,49], especially at the elite level, and to the best of our knowledge, this is one of the first studies to include several variables in order to assess anthropometric and body composition in elite women soccer players from a Portuguese BPI Ligue team. However, the sample size was derived from one team only and, therefore, future studies are required to generalize the findings.

Another interesting finding was related to the goalkeeper analysis, which showed that s-RPE and different body composition variables were similar regardless of player position and the squad average values. However, future studies are required to confirm this finding, since only one goalkeeper is an insufficient sample size from which to draw definite conclusions. Furthermore, more players for each position are required for an analysis across player positions.

Despite the importance of these results, and despite the use of tetra-polar and multifrequency bioimpedance equipment, such as InBody S10, to assess body composition and fluid distribution, we should address, as a limitation of this study, the use of a nonconsidered reference method. Another limitation was the fact that it was not possible to make comparisons among athletes of different field positions, as this would reduce the sampling power. Finally, and despite the fact that no differences were found in nutritional intake, this assessment was performed through a questionnaire at two time points, which should be better addressed in future studies. Even so, this study represents the actual training routine followed by the specific team analyzed. Therefore, more research is needed with larger numbers regarding soccer players and teams over an all-season period.

\section{Conclusions}

Coaches, physicians, nutritionists, and exercise physiologists should ensure they provide gender-specifications for optimizing performance. This study highlights information on the essential characteristics of successful women's' soccer team performance at three time-points throughout the sport season. For instance, the study showed that although some players may have performed different field roles and positions, their body composition characteristics improved over the season, which reveals that nutritional habits were controlled and, consequently, the intensity of training and matches did not affect the body composition variables.

This study presents a report using body composition data and internal training load simultaneously, which can be used as a reference for better body composition, training load and performance management for coaches and their staff. However, we recommend that future studies include a full season and other training load measures, such as global positioning systems, to amplify the present findings.

Author Contributions: Conceptualization, R.O.; methodology, R.O., J.P.B. and F.M.C.; software, R.O., A.M. and R.F.(Renato Fernandes); validation, R.O. and J.P.B.; formal analysis, R.O. and J.P.B.; investigation, R.O., R.F. (Ruben Francisco), A.M., J.P.B., H.N., F.M.C. and R.F. (Renato Fernandes); resources, R.O., R.F. (Renato Fernandes), A.M., J.P.B., H.N., F.M.C. and R.F. (Renato Fernandes); data curation, A.M. and R.F. (Renato Fernandes); writing—original draft preparation, R.O., R.F. (Ruben Francisco), A.M., J.P.B., H.N., F.M.C. and R.F. (Renato Fernandes); writing-review and editing, R.O., R.F. (Ruben Francisco), A.M., J.P.B. and F.M.C.; visualization, R.O., R.F. (Renato Fernandes), J.P.B. and F.M.C.; supervision, R.O. and F.M.C.; project administration, R.O., J.P.B. and R.F. (Renato Fernandes); funding acquisition, R.O. and J.P.B. All authors have read and agreed to the published version of the manuscript.

Funding: This research was funded by the Portuguese Foundation for Science and Technology, I.P., Grant/Award Number UIDP/04748/2020. The funders had no role in the design of the study; in the collection, analyses, or interpretation of data; in the writing of the manuscript, or in the decision to publish the results.

Institutional Review Board Statement: The study was conducted according to the guidelines of the Declaration of Helsinki and approved by the Ethics Committee of Polytechnic Institute of Santarém (252020Desporto). 
Informed Consent Statement: Written informed consent was obtained from the participants to publish this paper.

Data Availability Statement: The data presented in this study are available on request from the corresponding author.

Acknowledgments: The authors would like to thank the team's coaches and players for their cooperation during all data collection procedures.

Conflicts of Interest: The authors declare no conflict of interest.

\section{References}

1. Turner, A.N.; Stewart, P.F. Strength and conditioning for soccer players. Strength Cond. J. 2014, 36, 1-13. [CrossRef]

2. Sutton, L.; Scott, M.; Wallace, J.; Reilly, T. Body composition of English Premier League soccer players: Influence of playing position, international status, and ethnicity. J. Sports Sci. 2009, 27, 1019-1026. [CrossRef]

3. Silva, A.M. Structural and functional body components in athletic health and performance phenotypes. Eur. J. Clin. Nutr. 2019, 73, 215-224. [CrossRef] [PubMed]

4. Rienzi, E.; Drust, B.; Reilly, B.; Carter, J.E.L.; Martin, A. Investigation of anthropometric and work-rate profiles of elite South American international soccer players. J. Sports Med. Phys. Fit. 2000, 40, 162.

5. Silvestre, R.; West, C.; Maresh, C.M.; Kraemer, W.J. Body Composition And Physical Performance In Men's Soccer: Astudy Of A National Collegiate Athletic Association Division Iteam. J. Strength Cond. Res. 2006, 20, 177-183. [CrossRef]

6. Collins, J.; Maughan, R.J.; Gleeson, M.; Bilsborough, J.; Jeukendrup, A.; Morton, J.P.; Phillips, S.M.; Armstrong, L.; Burke, L.M.; Close, G.L.; et al. UEFA expert group statement on nutrition in elite football. Current evidence to inform practical recommendations and guide future research. Br. J. Sports Med. 2021, 55, 416. [CrossRef]

7. Silva, A.M.; Matias, C.N.; Santos, D.A.; Rocha, P.M.; Minderico, C.S.; Sardinha, L.B. Increases in intracellular water explain strength and power improvements over a season. Int. J. Sports Med. 2014, 35, 1101-1105. [CrossRef]

8. Silva, A.M.; Fields, D.A.; Heymsfield, S.B.; Sardinha, L.B. Body composition and power changes in elite judo athletes. Int. J. Sports Med. 2010, 31, 737-741. [CrossRef] [PubMed]

9. Silva, A.M.; Fields, D.A.; Heymsfield, S.B.; Sardinha, L.B. Relationship between changes in total-body water and fluid distribution with maximal forearm strength in elite judo athletes. J. Strength Cond. Res. 2011, 25, 2488-2495. [CrossRef]

10. Matković, B.R.; Mišigoj-Duraković, M.; Matković, B.; Janković, S.; Ružić, L.; Leko, G.; Miran, K. Morphological differences of elite Croatian soccer players according to the team position. Coll. Antropol. 2003, 27, 167-174. [PubMed]

11. Cárdenas-Fernández, V.; Chinchilla-Minguet, J.L.; Castillo-Rodríguez, A. Somatotype and body composition in young soccer players according to the playing position and sport success. J. Strength Cond. Res. 2019, 33, 1904-1911. [CrossRef]

12. da Silva, C.D.; Bloomfield, J.; Marins, J.C.B. A review of stature, body mass and maximal oxygen uptake profiles of U17, U20 and first division players in Brazilian soccer. J. Sports Sci. Med. 2008, 7, 309. [PubMed]

13. Owen, A.L.; Lago-Peñas, C.; Dunlop, G.; Mehdi, R.; Chtara, M.; Dellal, A. Seasonal body composition variation amongst elite european professional soccer players: An approach of talent identification. J. Hum. Kinet. 2018, 62, 177-184. [CrossRef]

14. Roelofs, E.; Bockin, A.; Bosch, T.; Oliver, J.; Bach, C.W.; Carbuhn, A.; Stanforth, P.R.; Dengel, D.R. Body Composition of National Collegiate Athletic Association (NCAA) Division I Female Soccer Athletes through Competitive Seasons. Int. J. Sports Med. 2020, 41, 766-770. [CrossRef] [PubMed]

15. Fanchini, M.; Ferraresi, I.; Petruolo, A.; Azzalin, A.; Ghielmetti, R.; Schena, F.; Impellizzeri, F.M. Is a retrospective RPE appropriate in soccer? Response shift and recall bias. Sci. Med. Footb. 2017, 1, 53-59. [CrossRef]

16. Faul, F.; Erdfelder, E.; Lang, A.-G.; Buchner, A. G* Power 3: A flexible statistical power analysis program for the social, behavioral, and biomedical sciences. Behav. Res. Methods 2007, 39, 175-191. [CrossRef] [PubMed]

17. Oliveira, R.; Brito, J.P.; Loureiro, N.; Padinha, V.; Nobari, H.; Mendes, B. Will Next Match Location Influence External and Internal Training Load of a Top-Class Elite Professional European Soccer Team? Int. J. Environ. Res. Public Health 2021, 18, 5229. [CrossRef]

18. Arazi, H.; Mirzaei, B.; Nobari, H. Anthropometric profile, body composition and somatotyping of national Iranian cross-country runners. Turk. J. Sport Exerc. 2015, 17, 35-41. [CrossRef]

19. Nobari, H.; Polito, L.F.T.; Clemente, F.M.; Pérez-Gómez, J.; Ahmadi, M.; Garcia-Gordillo, M.Á.; Garcia-Gordillo, M.Á.; Silva, A.F.; Adsuar, J.C. Relationships between training workload parameters with variations in anaerobic power and change of direction status in elite youth soccer players. Int. J. Environ. Res. Public Health 2020, 17, 7934. [CrossRef] [PubMed]

20. Lohman, T.G.; Roche, A.F.; Martorell, R. Anthropometric Standardization Reference Manual, 1st ed.; Human Kinetics Books: Champaign, IL, USA, 1988.

21. Yang, E.M.; Park, E.; Ahn, Y.H.; Choi, H.J.; Kang, H.G.; Cheong, H.I.; Ha, I.S. Measurement of fluid status using bioimpedance methods in Korean pediatric patients on hemodialysis. J. Korean Med. Sci. 2017, 32, 1828. [CrossRef]

22. Buckinx, F.; Reginster, J.-Y.; Dardenne, N.; Croisiser, J.-L.; Kaux, J.-F.; Beaudart, C.; Slomian, J.; Bruyère, O. Concordance between muscle mass assessed by bioelectrical impedance analysis and by dual energy X-ray absorptiometry: A cross-sectional study. BMC Musculoskelet. Disord. 2015, 16, 60. [CrossRef] [PubMed] 
23. Martins, A.D.; Oliveira, R.; Brito, J.P.; Costa, T.; Ramalho, F.; Pimenta, N.; Santos-Rocha, R. Phase angle cutoff value as a marker of the health status and functional capacity in breast cancer survivors. Physiol. Behav. 2021, 235, 113400. [CrossRef]

24. Rahmat, A.J.; Arsalan, D.; Bahman, M.; Hadi, N. Anthropometrical profile and bio-motor abilities of young elite wrestlers. Phys. Educ. Stud. 2016, 20, 63-69. [CrossRef]

25. Steward, A.; Marfell-Jones, M.; Olds, T.; de Ridder, H. International Standards for Anthropometric Assessment; International Society for the Advancement of Kinanthropometry: Lower Hutt, New Zealand, 2011.

26. Borg, G. Perceived exertion as an indicator of somatic stress, Scand. J. Rehabil. Med. 1970, 2, 92-98.

27. Burgess, D.; Drust, B.; Williams, M. Developing a physiology-based sports science support strategy in the professional game. Sci. Soccer Dev. Elite Perform. 2013, 13, 372-389.

28. Foster, C. Monitoring training in athletes with reference to overtraining syndrome. Occup. Health Ind. Med. 1998, 4, 189. [CrossRef]

29. Foster, C.; Florhaug, J.A.; Franklin, J.; Gottschall, L.; Hrovatin, L.A.; Parker, S.; Pamela, D.; Christopher, D. A new approach to monitoring exercise training. J. Strength Cond. Res. 2001, 15, 109-115.

30. Hopkins, W.G. Spreadsheets for analysis of controlled trials, with adjustment for a subject characteristic. Sportscience 2006, 10, 46-50.

31. Peart, A.N.; Nicks, C.R.; Mangum, M.; Tyo, B.M. Evaluation of seasonal changes in fitness, anthropometrics, and body composition in collegiate division II female soccer players. J. Strength Cond. Res. 2018, 32, 2010-2017. [CrossRef]

32. Minett, M.M.; Binkley, T.B.; Weidauer, L.A.; Specker, B.L. Changes in body composition and bone of female collegiate soccer players through the competitive season and off-season. J. Musculoskelet. Neuronal Interact. 2017, 17, 386.

33. Francisco, R.; Matias, C.N.; Santos, D.A.; Campa, F.; Minderico, C.S.; Rocha, P.; Heymsfield, S.B.; Lukaski, H.; Sardinha, L.B.; Silva, A.M. The Predictive Role of Raw Bioelectrical Impedance Parameters in Water Compartments and Fluid Distribution Assessed by Dilution Techniques in Athletes. Int. J. Environ. Res. Public Health 2020, 17, 759. [CrossRef] [PubMed]

34. Marini, E.; Campa, F.; Buffa, R.; Stagi, S.; Matias, C.N.; Toselli, S.; Sardinha, L.B.; Silva, A.M. Phase angle and bioelectrical impedance vector analysis in the evaluation of body composition in athletes. Clin. Nutr. 2019, 39, 447-454. [CrossRef]

35. Ribeiro, A.S.; Avelar, A.; Santos, L.D.; Silva, A.M.; Gobbo, L.A.; Schoenfeld, B.J.; Sardinha, E.S.C. Hypertrophy-type Resistance Training Improves Phase Angle in Young Adult Men and Women. Int. J. Sports Med. 2017, 38, 35-40. [CrossRef]

36. Barbosa-Silva, M.C.; Barros, A.J.; Wang, J.; Heymsfield, S.B.; Pierson, R.N., Jr. Bioelectrical impedance analysis: Population reference values for phase angle by age and sex. Am. J. Clin. Nutr. 2005, 82, 49-52. [CrossRef]

37. Norman, K.; Stobaus, N.; Zocher, D.; Bosy-Westphal, A.; Szramek, A.; Scheufele, R.; Smoliner, C.; Pirlich, M. Cutoff percentiles of bioelectrical phase angle predict functionality, quality of life, and mortality in patients with cancer. Am. J. Clin. Nutr. 2010, 92, 612-619. [CrossRef] [PubMed]

38. Nescolarde, L.; Yanguas, J.; Lukaski, H.; Alomar, X.; Rosell-Ferrer, J.; Rodas, G. Localized bioimpedance to assess muscle injury. Physiol. Meas. 2013, 34, 237-245. [CrossRef]

39. Nescolarde, L.; Yanguas, J.; Medina, D.; Rodas, G.; Rosell-Ferrer, J. Assessment and follow-up of muscle injuries in athletes by bioimpedance: Preliminary results. Conf. Proc. IEEE Eng. Med. Biol. Soc. 2011, 2011, 1137-1140.

40. Norman, K.; Wirth, R.; Neubauer, M.; Eckardt, R.; Stobaus, N. The bioimpedance phase angle predicts low muscle strength, impaired quality of life, and increased mortality in old patients with cancer. J. Am. Med. Dir. Assoc. 2015, 16, 173-e17. [CrossRef] [PubMed]

41. Gonzalez, M.C.; Barbosa-Silva, T.G.; Bielemann, R.M.; Gallagher, D.; Heymsfield, S.B. Phase angle and its determinants in healthy subjects: Influence of body composition. Am. J. Clin. Nutr. 2016, 103, 712-716. [CrossRef] [PubMed]

42. Mascherini, G.; Gatterer, H.; Lukaski, H.; Burtscher, M.; Galanti, G. Changes in hydration, body-cell mass and endurance performance of professional soccer players through a competitive season. J. Sports. Med. Phys. Fit. 2015, 55, 749-755.

43. Kenney, W.L.; Wilmore, J.H.; Costill, D.L. Physiology of Sport and Exercise, 6th ed.; Human Kinetics Books: Champaign, IL, USA, 2015.

44. Haussinger, D.; Lang, F.; Gerok, W. Regulation of cell function by the cellular hydration state. Am. J. Physiol. Endocrinol. Metab. 1994, 267, E343-E355. [CrossRef]

45. Haussinger, D.; Roth, E.; Lang, F.; Gerok, W. Cellular hydration state: An important determinant of protein catabolism in health and disease. Lancet 1993, 341, 1330-1332. [CrossRef]

46. Mara, J.K.; Thompson, K.G.; Pumpa, K.L.; Ball, N.B. Periodization and physical performance in elite female soccer players. Int. J. Sports Physiol. Perform. 2015, 10, 664-669. [CrossRef]

47. Renfree, A.; Martin, L.; Micklewright, D.; Gibson, A.S.C. Application of decision-making theory to the regulation of muscular work rate during self-paced competitive endurance activity. Sports Med. 2014, 44, 147-158. [CrossRef]

48. Ferraz, R.; Goncalves, B.; Coutinho, D.; Marinho, D.A.; Sampaio, J.; Marques, M.C. Pacing behaviour of players in team sports: Influence of match status manipulation and task duration knowledge. PLoS ONE 2018, 13, e0192399. [CrossRef]

49. Julian, R.; Skorski, S.; Hecksteden, A.; Pfeifer, C.; Bradley, P.S.; Schulze, E.; Meyer, T. Menstrual cycle phase and elite female soccer match-play: Influence on various physical performance outputs. Sci. Med. Footb. 2020, 5, 97-104. [CrossRef] 